\title{
À sombra do castanheiro: entre o discurso do manicômio e as paredes da solidão
}

DOI: https://doi.org/10.5935/1984-9044.20200022

\author{
Ana Júlia Vieira Zucchi', Bruno Ferreira Emerich ${ }^{2}$ \& Giovana Pellati - \\ Universidade Estadual de Campinas (UNICAMP)
}

Resumo: No atual contexto da Reforma Psiquiátrica, faz-se necessário pensar de que forma o paradigma manicomial tem se atualizado nos serviços de saúde mental e para além deles. Neste trabalho, propõe-se discutir tais aspectos a partir do relato de experiência de uma residente em uma Enfermaria de Psiquiatria em Hospital Geral de um município de grande porte. Para tal, faz-se uma analogia com cenas da obra Cem Anos de Solidão, de Gabriel Garcia Márquez, para entender quais são as partes e os autores envolvidos nesse processo. Entendem-se, assim, as possíveis consequências de discursos e práticas manicomiais, para o usuário do serviço de saúde mental, que impactam na sua subjetividade e na construção de seu lugar dentro da sociedade..

PALAVRAS-CHAVE: reforma psiquiátrica; atenção psicossocial; psicologia e literatura; saúde mental; hospital geral.

\section{The shade of the chestnut tree: between the asylum expressions and the walls of loneliness}

Abstract: In the current context of Psychiatric Reform, it is necessary to think about how the mental asylum paradigm has been updated in mental health services and beyond. In this paper, it is proposed to discuss such aspects based on the experience report of a resident in a Psychiatry Infirmary at a General Hospital in a large city. To this end, an analogy is made with scenes from the book A Hundred Years of Solitude, by Gabriel Garcia Márquez, to comprehend the parts involved in this process. Thus, it is understood the possible consequences of speeches and asylum practices for the users of the mental health services, which impact on their subjectivity and construction of their place within society.

KEY WORDS: psychiatric reform; psychosocial attention; psychology and literature; mental health; general hospital.

1 ORCID: https://orcid.org/0000-0003-0436-3733

2 ORCID: http://orcid.org/0000-0001-7246-5809 


\section{Prólogo}

osé Arcádio Buendía, personagem da obra Cem Anos de Solidão (Marquez, 1967), foi taxado como louco em certo momento de sua vida. Desde o início do livro, é caracterizado como alguém curioso e criativo, um sujeito com ideias extravagantes que não mede esforços para concretizá-las. Porém, em certa ocasião, seu filho e conhecidos próximos o encontraram em tal estado que os fez acreditar que tais ideias ultrapassaram o limite da coerência e, não sabendo como lidar com a situação e identificando José Arcádio como um perigo para os outros a sua volta, decidem por prendê-lo em um castanheiro localizado no quintal de sua casa. José Arcádio luta e reluta, mas a força de 20 homens é maior, e finalmente conseguem amarrá-lo.

Enquanto amarrado, não deixa de ter o mínimo para garantia de sua sobrevivência. Todas as refeições Ihe são servidas. É construído um teto de viga sobre sua cabeça, fazem-lhe visitas, trazem as notícias e jogam damas com ele. Apesar de conversar, brincar, jogar, discutir, são poucas as pessoas que questionam a necessidade de José Arcádio estar preso.

Até que chega o dia em que, reconhecendo sua melhora, tiram as cordas que aprisionavam José Arcádio e o chamam para voltar para casa. Ele, por sua vez, não se move, sendo necessário que o carreguem até seu quarto. Amanhecido o outro dia, não encontram José Arcádio no quarto e se deparam com ele de volta ao castanheiro, tendo feito sozinho seu caminho até lá. Novamente o carregam, dessa vez sendo preciso que mais pessoas o façam, pois José Arcádio está mais pesado do que no dia anterior. É levado novamente até seu quarto. No outro dia, José Arcádio é encontrado com um aspecto diferente: ainda mais pesado, seu quarto todo está com cheiro forte de árvore, terra e folhas, onde ele mesmo está se transformando no castanheiro ao qual estava amarrado. 
Abro esse trabalho com essa cena, pois é com uma analogia a ela que me proponho a discutir sobre as diferentes formas de expressão do Manicômio, o impacto que ele tem na construção da subjetividade de cada sujeito e os diferentes atores e partes envolvidas nesse processo. Para tal, uso como cenário deste trabalho minha experiência em uma Enfermaria de Psiquiatria em um Hospital Geral de um município de grande porte.

Porém, para que se possa pensar em ofertas de cuidado e tratamento, é necessário entender de que forma a loucura é lida nesse espaço.

\section{Saúde Mental e Hospital Geral}

\begin{abstract}
A Reforma Psiquiátrica no Brasil se consolidou contemporaneamente à Reforma Sanitária, tendo seu início na década de 1970, em um contexto em que se defendia uma nova maneira de produção de saúde e concepção de doença, considerando o sujeito por trás dela e os determinantes sociais envolvidos nesse processo. A referência de tratamento para aqueles em intenso sofrimento psíquico eram as instituições de exclusão (manicômio e hospitais psiquiátricos), refletindo e sustentando o estigma construído em torno do louco que simboliza perigo e alienação e deve, portanto, ser isolado e controlado.
\end{abstract}

Dessa forma, a Reforma Psiquiátrica se constrói através de um processo de desinstitucionalização que, para além de deslocar o cuidado centralizado em manicômios e hospitais para a comunidade, visa também a uma nova forma de concepção da loucura que diz respeito a diferentes modos de expressão e subjetivação, produzindo novos lugares sociais para aqueles anteriormente isolados e tutelados, tendo assim como pressuposto fundamental o resgate de autonomia e cidadania desses sujeitos. Porém, por diferentes forças (como o crescimento da indústria dos psicofármacos, paradigma 
da Psiquiatria tradicional, dentre outros), deparamo-nos ainda com importantes divergências políticas e ideológicas nesse espectro.

Costa Junior e Medeiros (2007) trazem uma distinção entre o conceito da loucura no âmbito da Saúde Mental e da Psiquiatria chamada tradicional. Segundo os autores, a leitura que se faz da loucura na Psiquiatria tradicional é a de uma entidade nosológica autônoma, que acaba por ser nomeada através de diagnósticos baseados em uma classificação de sintomas, para assim ser possível identificá-la e estabelecer um tratamento quase que exclusivamente farmacológico, visando a eliminação desses sintomas do comportamento dos indivíduos.

Em contraponto, os autores trazem a abordagem da Saúde Mental (também caracterizada por eles como Saúde Mental na Atenção Psicossocial) estruturada a partir dos princípios da Reforma Psiquiátrica Brasileira. Nesta, a noção da loucura se dá com base em uma experiência singular de cada sujeito, cuja expressão tem relação íntima com sua história e cultura na qual está inserido. Entende-se a loucura como uma experiência dotada de sentido que provém da subjetividade daquele que a vive, englobando, para além da abrangência individual, o fenômeno social e coletivo (Costa Junior e Medeiros, 2007).

Os Leitos de Saúde Mental em Hospital Geral, regulamentados pela Lei da Reforma Psiquiátrica 10.216/2001 (Brasil, 2001), entram como dispositivo da Rede de Atenção Psicossocial também para que os manicômios ou hospitais psiquiátricos deixem de assumir qualquer papel na atenção à saúde mental. $\mathrm{O}$ acolhimento de usuários nesse serviço deve ser feito depois de uma avaliação de vulnerabilidade e risco psicossocial, em conjunto entre a equipe do Hospital Geral e com a equipe de referência de cuidado daquele usuário, levando em consideração a necessidade de um espaço de continência que apenas o Hospital poderia ofertar, a necessidade de cuidados e monitoramentos clínicos (incluindo o acompanhamento medicamentoso) associados à manifestação psiquiátrica, dentre outros. 
Porém, as práticas que visem à expressão, elaboração e transformação do sofrimento psíquico também deveriam ser incorporadas como ofertas nesse espaço (Kimati, Ferigato e Chanchetti, 2019).

Já a Enfermaria de Psiquiatria, por sua vez, funciona de maneira distinta. A lógica de cuidado segue o paradigma biomédico. A porta da enfermaria se mantém o tempo todo trancada e vigiada - não há convivência entre os usuários que estão ali internados com outros usuários do Hospital, reforçando a representação social de preconceito e controle, isolamento e segregação. Não há reuniões de equipe para que os diferentes núcleos presentes possam discutir os casos de forma interdisciplinar, e a comunicação com a rede intersetorial não é prioritária, sendo que muitos dos casos acabam por continuar o tratamento de forma ambulatorial dentro do próprio hospital. Tais intervenções são repetições de práticas que se sustentam pela manutenção de um estigma construído historicamente acerca do louco como um sujeito incapaz, perigoso e destituído de afeto.

A Enfermaria onde esse trabalho é realizado se nomeia e se caracteriza como uma Enfermaria de Psiquiatria. Sendo assim, propomos discutir a concepção de sofrimento psíquico e as consequentes ofertas de tratamento realizadas ali e de que forma os sujeitos acabam por ser atravessados por uma lógica que os reduz a sintomas, tendo assim suas existências silenciadas. Para tal, a discussão se dará pelo desmembramento da cena literária anteriormente descrita, expondo os diferentes papéis desempenhados por cada uma das partes: "Josés Arcádios", com o intuito de entender quem são aqueles que, considerados loucos, devem ser tratados; "a Comida, o Teto, as Notícias e as Visitas", com a proposta de estudar as ofertas caracterizadas como de cuidado apresentadas a essas pessoas; e "o Castanheiro", buscando finalmente analisar e articular todo esse processo pelo qual o Manicômio se manifesta a ponto de se tornar parte daquele que é sua vítima. 


\section{José Arcádios}

José Arcádio Buendía é apresentado como um homem "cuja desatada imaginação ia sempre mais longe que o engenho da natureza, e até mesmo do milagre e da magia" (Marquez, 1973, p. 8). Na aldeia onde morava, Macondo, fundada por ele mesmo, todas as casas eram construídas à imagem e semelhança da sua própria, sendo importante referência dentro do povoado. Empreendedor, organizou o comércio na aldeia que pouco a pouco foi se transformando em cidade. Inteligente e curioso, foi cartógrafo, astrônomo e alquimista sem saber que recebia esses nomes para fazer o que fazia. Passou a vida casado com sua prima, Úrsula, com quem criou dois filhos e duas filhas. Ensinou-os a ler, escrever, fazer contas e não os poupou de seu conhecimento e imaginação.

Foi julgado louco em diferentes momentos de sua vida. Quando José Arcádio se deslumbrava com alguma coisa, passava a se dedicar inteira e exclusivamente à descoberta. Deixava de se cuidar, parava de comer e de dormir. Era sempre Úrsula quem o acolhia, com dureza e cuidado, pouco a pouco ajudando José Arcádio a retomar o contato com o mundo ao seu redor. Foi na sua ausência que José Arcádio, após perder um grande amigo e entender o funcionamento da roda, deixou de reconhecer o passar do tempo, sendo levado a acreditar que vivia sempre o mesmo dia. Numa tentativa de fazer com que algo mudasse, começou a quebrar todas as coisas da casa, momento em que seu filho e seus vizinhos o encontraram, seguraram e amarraram, entendendo que assim evitariam uma possível tragédia.

Após essa breve introdução da história de José Arcádio, apresentamos a seguir outros dois personagens que vão compor a discussão deste trabalho. Tal apresentação será feita em forma de narrativa de casos que foram acompanhados pela residente enquanto 
parte da equipe na Enfermaria de Psiquiatria. A escrita foi construída a partir da retomada de diários de campo, relatando o cotidiano do encontro com os usuários em atendimentos, grupos

\section{Alek}

Foram vários os lugares em que Alek pediu ajuda antes de chegar ao Hospital. Chegou solicitando uma cirurgia, pois naquele mesmo hospital, durante um exame em um momento anterior, haviam instalado uma máquina no seu cérebro que lhe transmitia pensamentos incoerentes e violentos e, entendendo que estava sendo encaminhado para os preparativos da cirurgia, foi internado em uma enfermaria de Psiquiatria.

A cirurgia que estaria para chegar no dia seguinte nunca chega, e os remédios dados para expelir a tal máquina também não funcionam - as imagens de violência e as vozes continuam a ser transmitidas. Até que houve um momento em que parecia que ia acontecer, fez até um exame do coração, subiu até a sala de com familiares e discussão com a equipe. Todos os nomes são fictícios, inspirados por outros personagens da literatura que também carregaram em suas histórias o estigma da loucura. cirurgia, colocaram alguns aparelhos na sua cabeça e apagou, apagou para não sentir o choque, o corpo tremendo em convulsões. Mas quando acordou a máquina ainda estava lá. Tantas coisas que se perderam, lembranças, momentos, essa máquina bem que podia ter sido uma delas, mas não foi. Todos os dias tudo se repete e a cirurgia não chega, a violência se estende para fora da cabeça. Um dia, Alek pula pela janela, mas volta para a porta do lugar da onde acabou de fugir, volta a pedir por ajuda sem reconhecer a quem pedia, pede por uma cirurgia porque um dia, naquele mesmo hospital, durante um exame em um momento anterior, haviam instalado uma máquina em seu cérebro que lhe transmitia pensamentos incoerentes e 
INTERAÇÕES SOCIAIS DE CRIANÇAS DE TRÊS A QUATRO ANOS EM INSTITUIÇÃO

DE EDUCAÇÃO INFANTIL

violentos. As portas são abertas, a ajuda é oferecida em forma de uma mão estendida que leva Alek até sua cama para ser contido.

(Todos os dias tudo se repete) E passados já três meses na internação, Alek acordou em um dia acreditando estar em uma prisão. Seu julgamento seria no dia seguinte e, por isso, estava elaborando sua defesa. Pediu uma cópia da Constituição Federal do Brasil para que ele pudesse provar que fora injustamente encarcerado. $O$ documento construído foi inteiramente embasado no Art. 5o da atual Constituição (mais

\section{Janina}

Duas horas e trinta minutos e três ônibus para seis horas de ida ao trabalho, mais duas horas e trinta minutos e três ônibus para voltar, busca a filha na escola, volta para o quarto que chama de casa no terreno dos fundos da casa da mãe, terreno este que também divide com os irmãos e sobrinhos. Mãe solo, que sabe que não compensa perder um dia de especificamente no Inc IX), que diz respeito à liberdade de expressão:

Art. 5ำ Todos são iguais perante a lei, sem distinção de qualquer natureza, garantindo-se aos brasileiros e aos estrangeiros residentes no País a inviolabilidade do direito à vida, à liberdade, à igualdade, à segurança e à propriedade, nos termos seguintes: IX - é livre a expressão da atividade intelectual, artística, científica e de comunicação, independentemente de censura ou licença (Brasil, 1988, $s / p)$. trabalho para ir, uma vez na semana, ao tratamento, porque o dinheiro de um dia de trabalho faz falta para comprar comida, pagar conta, comprar remédio, sobreviver. Mesmo assim, arranja tempo de pegar mais dois ônibus para passar por uma consulta de meia hora para dizer que está difícil sim, doutor, que as vozes aumentaram, que não sente vontade de 
acordar, que tem medo de machucar a filha, porque é isso que a voz diz, diz para machucar a menina. E a mulher vai para a internação de Psiquiatria porque se entende que precisa de um ambiente continente, e faz eletroconvulsoterapia e toma remédio e faz eletroconvulsoterapia para potencializar o remédio, quebrou o dente em um desses procedimentos, mas tudo bem, é só um detalhe perto do quanto melhorou, agora está sorrindo, conversando, tem saudades da filha. Refere ouvir vozes? Não. Então, deixa ela passar o fim de semana em casa e quando voltar a gente vê a alta, mas o fim de semana não foi bom, os sintomas voltaram, as vozes mais altas, Foi muito difícil, doutor, Então fica mais uma semana, vamos fazer de novo do mesmo jeito, no final da semana a gente tenta uma outra licença, e de novo é difícil, e de novo volta e tenta do mesmo jeito, e de novo, e de novo, e de novo. Parece que nada resolve, "Fica bem aqui, mas quando volta para casa piora, não tem o que fazer", um médico discute o caso da mulher do outro lado, parece tão afastado dela, mas é só esse portão que separa os dois como se colocasse quilômetros de distância entre o de fora e o de dentro, e o tempo só não é o mesmo porque lá fora ele passa, e o doutor repete que não há o que fazer, não se sabe o que mais oferecer, para concluir que "Não que esteja defendendo, mas eram essas as pessoas que ficavam institucionalizadas em manicômios".

\section{A comida, o teto, as visitas, as notícias}

Foram vários os arranjos pensados para que José Arcádio vivesse na melhor qualidade possível dentro da situação em que foi colocado. Para que seus pulsos não ficassem machucados, o deixaram amarrado apenas pela cintura. Imediatamente foi construído um teto de viga em cima de sua cabeça para protegê- 
lo de queimaduras de sol. A refeição que Ihe era servida era farta, as visitas eram frequentes. Nunca deixaram de lhe trazer notícias, sabendo que José Arcádio era um homem interessado no mundo ao seu redor.

Apesar do cuidado e atenção que José Arcádio vinha recebendo naquelas condições, ele ainda assim estava amarrado ao Castanheiro e de lá não podia sair - não caminhava pela cidade, não fazia experimentos, não trabalhava em seu laboratório, dentre outras coisas que faziam parte do seu desejo e que não necessariamente eram bem aceitas por aqueles que o cercavam.

Dentro de um Hospital em que a concepção predominante do sofrimento psíquico é a de base fundamentalmente orgânica, corre-se o risco de que as práticas adotadas para o tratamento se assemelhem aos cuidados ofertados a José Arcádio. Uma vez elaborado um diagnóstico, delimitando assim o sofrimento em condição de doença, o caminho mais provável a se seguir é o que visa a uma inexistente cura.
A loucura atestada cientificamente é a validada por diagnósticos. O diagnóstico, por sua vez, é elaborado a partir de uma somatória de sintomas de diferentes ordens, avaliado pelo médico psiquiatra pela própria observação e/ou entrevistas e atendimentos com familiares e com o próprio sujeito. Dentre os sintomas para diagnósticos psiquiátricos mais comuns, constam a apatia, a agressividade, alucinações, oscilação de humor, ouvir vozes, dentre outros. Hoje, a definição e orientação para formulação diagnóstica de "transtornos mentais" é feita com base no Manual Diagnóstico e Estatístico de Transtornos Mentais (DSM), estando atualmente na sua 5a edição. Desde sua 1a edição, em 1952, o número de categorias diagnósticas aumentou em mais de 250\% (Ferrazza, 2013). O tratamento conta principalmente com o uso de psicofármacos, sendo estes e a eletroconvulsoterapia (ECT) os dois principais recursos utilizados no cenário deste trabalho, pois é a partir deles que se dará a discussão.

Tais recursos são manejados para agirem diretamente sobre o sintoma. Quando Janina chega para ser internada, 
entende-se que o motivo de sua vinda se dá pela desestabilização em uma rotina que precisa ser retomada. O objetivo da internação é o de fazê-la voltar a trabalhar, cuidar da casa, da filha, e manter estabilidade no que diz respeito à continuidade do tratamento, assim como anteriormente.

Entendendo exclusivamente que o motivo que gerou instabilidade e fragilização na estrutura de sua vida foi o agravamento das vozes que escutava - e não o contrário -, seu tratamento se baseia na utilização de antipsicóticos, no intuito de cessar as vozes, e antidepressivos, para que saísse do estado de extremo cansaço em que ela se encontrava. Quando Janina retornou para sua casa e os sintomas voltaram, optou-se pela realização da ECT, com a intenção de potencializar o efeito do antipsicótico. Porém, assim como apontado por Silva (2012), ainda não há evidências de correlação direta entre o procedimento (ECT) e o efeito por vezes alcançado. Assim como outros tratamentos na Psiquiatria, a ECT se fortaleceu, como procedimento, com a observação de resultados considerados eficazes durante intervenções (Silva, 2012).

A partir do momento em que se coloca o sintoma à parte, seja ele qual for, ocorre uma descontextualização: este passa a ser lido isoladamente e, portanto, negase a compreensão de que é a manifestação de uma singularidade do sujeito, dentro de uma história e de um contexto, a forma de expressão de um sofrimento. Quando Janina vem para sua consulta pedindo por ajuda, é possível que a equipe que a tenha avaliado não tenha percebido que os sintomas identificados poderiam expressar um sofrimento que vem de uma rotina exaustiva e por muitas vezes opressora. As condutas pensadas não têm a capacidade de agir em cima disso. É natural que, ao voltar para sua casa, entrando em contato com aquilo que a adoece, os sintomas voltem, pois, para além de uma alteração bioquímica, estes simbolizam um sofrimento que não são acessados por essas intervenções.

Vale ainda ressaltar que tais condutas são pensadas por uma equipe predominantemente médica, a partir de uma avaliação inicial também 
predominantemente médica de que aquela pessoa estava em crise. As propostas de tratamento não são buscadas de forma a promover autonomia, tampouco colocam o sujeito como protagonista da própria história, assim como preconizado pelos princípios da Reforma Psiquiátrica. Reconhecendo que os comportamentos e pensamentos considerados loucos têm uma explicação exclusivamente biológica, entende-se que o sujeito que os detém possui pouca autonomia com relação a eles, desautorizando-o de intencionalidade sobre seus próprios atos. Justifica-se, a partir da cientificidade de um diagnóstico que é meramente a descrição de sintomas, o controle exercido através de técnicas asilares e/ou químicas de contenção, fortalecendo e legitimando a estigmatização da loucura na vida em sociedade (Costa Junior e Medeiros, 2007).

O tratamento de Alek não se dá de forma tão distinta. Seu caso chega para a equipe como uma esquizofrenia desencadeada pelo uso de substâncias psicoativas (SPAs). Na tentativa de cessar as vozes, também foram utilizados os recursos aos antipsicóticos e ao ECT. O uso deste último se deu também na intenção de "contê-lo", pois parte da equipe se referia exausta com os incessantes pedidos de Alek. Assim, a ECT foi usada a partir da justificativa de que os remédios não estavam tendo os efeitos esperados alcançados, mas também no intuito de fazê-lo ficar menos agitado: "ECT para conter agitação e agressividade", era a anotação que constava no seu documento de condutas clínicas na Enfermaria.

Entendendo o uso de SPAs como central no desencadear do seu diagnóstico, a equipe se esforçava para fazer Alek entender que esse uso era extremamente nocivo e a única forma de seu tratamento dar continuidade seria se ele concordasse em não fazer uso de tais substâncias novamente. Eram mínimos os espaços abertos para que Alek falasse sobre seu uso, a relação que mantinha com a droga e que lugar ela ocupava no seu cotidiano. Dessa forma, as abordagens de Redução de Danos trazidas eram constantemente boicotadas, pois não estavam de acordo com o restante da equipe responsável 
pela alta de Alek, razão pela qual a sua adesão à lógica de abstinência se tornou condição para que saísse do Hospital.

O silenciamento provocado pela equipe é nitidamente expressado quando Alek elabora e escreve um documento de defesa baseado no Artigo 5o da Constituição Federal, que diz respeito à liberdade de expressão. Constantemente contido química e mecanicamente, não reconhecido no seu direito de escolha e sem autonomia com relação à forma que pretende viver sua vida, Alek se reconhece, através do delírio, como injustamente preso, uma vez que teve seu direito de livre expressão ferido.

Em contraponto a essa forma de oferta de tratamento está a Atenção Psicossocial que, na sua abordagem do singular e do coletivo, cria cotidianamente formas de resistir à mesmice e a essa mesma sociedade intolerante. Tal abordagem visa a construções de novas formas de habitar o mundo, de se construir relações sociais e da produção a partir do desejo. São essas estratégias, pautadas por uma ética de respeito à diferença, que o cuidado acerca do sujeito em sofrimento psíquico se estende para além dos espaços ditos de tratamento, abarcando princípios e valores que visam reinventar toda uma sociedade, transformando mentalidades, hábitos $\mathrm{e}$ costumes que silenciam singularidades e histórias (Yasui, 2009).

É importante ressaltar que aqui foram discutidas apenas as intervenções realizadas pela utilização de psicofármacos e a ECT. Porém, tal silenciamento não é exclusivo dessas práticas, da mesma forma que o uso de psicofármacos é um recurso terapêutico de extrema importância quando utilizado de maneira distinta da relatada aqui. Tantas outras práticas, como a psicoterapia, as atividades grupais e familiares, dentre outras - se usadas de forma conivente com um poder que busca a adaptação do sujeito à sociedade, tirando-Ihe a liberdade de ser diferente - são igualmente opressoras e violentas. 


\section{O castanheiro}

Quando José Arcádio volta ao Castanheiro mesmo após ser desamarrado e levado de volta para sua casa, é porque não são mais as correntes que o seguram naquele lugar. José Arcádio pesa mais do que seu próprio corpo, e a cada vez que vão retirá-lo do Castanheiro para trazê-lo de volta ele está mais pesado. Uma vez instalado dentro de casa, passa a tomar outro aspecto que não o seu comum, um cheiro forte de terra toma conta do quarto e desenha-se um José Arcádio se tornando o próprio Castanheiro no qual há pouco esteve amarrado.

Faço a analogia do Castanheiro ao Manicômio, pensando nessa estrutura que aprisiona sujeitos, mas que não necessariamente precisa estar concretizada em forma de qualquer tipo de construção para cumprir seu objetivo de silenciar e violentar existências.
Considera-se para esta discussão a definição de Goffman (1961), que descreve o manicômio enquanto uma Instituição Total. Dentre as características apontadas pelo autor, destaco o processo descrito como a mortificação do eu e a violação da autonomia do ato, que tem como consequência a construção de uma nova identidade para o doente/louco. Para tal, se estabelece uma organização que tem como principal função a vigilância e o controle desses sujeitos e suas necessidades, visando ao silenciamento de seus desejos (Goffman, 1961).

A Enfermaria de Psiquiatria não se caracteriza como Instituição Total. Porém, vê-se a repetição desses processos que investem no silenciamento e mortificação do eu. Tais processos, atualizados a céu aberto, são denominados por Emerich, Campos e Passos (2014) como práticas totais. São práticas que normalizam os processos de 
vida e universalizam formas de sentir, agir e pensar.

Os casos e tratamentos propostos de Alek e Janina partiram de princípios semelhantes, apesar de realidades distintas. Janina já tinha uma rotina firmada, com atividades como trabalho, cuidar da casa e da família já estabelecidas, enquanto Alek, por estar afastado da faculdade, estava em um momento em que seu dia a dia estava bastante instável, sem compromissos fixos ou objetivos delimitados por ele mesmo, muito por conta da desorganização causada pela intensidade das vozes.

Através da escuta de outra psicóloga, Janina consegue dizer que não está satisfeita com a forma como tem conduzido sua vida, expressando, após diversos atendimentos com a residente, o desejo de poder voltar a estudar, participar de cursos, encontrar outro trabalho. Também foi manifestada por ela a dificuldade de manter o emprego atual, por conta da distância e tempo consumidos para ir até o local de trabalho.
Essa psicóloga, entendendo que o tempo e o espaço da internação não seriam suficientes para atender às demandas trazidas por Janina, articulou com seu CAPS de referência a condução desse projeto pactuado em conjunto com a usuária. Enquanto ainda estava internada, foram apresentados à Janina diversos locais que ofereciam cursos gratuitos pela cidade, e assim Janina pôde procurar por um caminho que fosse de seu desejo e interesse.

Porém, parte da equipe ainda colocava o diagnóstico de Janina não somente como um obstáculo, mas como um fator de impossibilidade para a realização do que ela havia expressado como seu desejo. Ao contrário da psicóloga que assumiu a escuta de Janina, a equipe entendia que a mudança em sua rotina envolvia enormes riscos para ela e, por conta disso, deveria aproveitar o que já havia conquistado até agora.

Janina caminha comigo em frente à sala onde ocorrem as reuniões de equipe e diz: "não gosto desta sala porque é aqui que vocês decidem nossa vida". O paradigma manicomial toma o formato de um tratamento que coloca como 
condição sua readequação e adaptação a essa rotina que a apagava, destituindo Janina de seus desejos e direitos. A distância que se coloca entre o sujeito e o direcionamento do seu próprio tratamento acaba por escancarar a falta de aposta que se tem na autonomia e no protagonismo do sujeito na sua própria vida.

Relembrando, Alek foi submetido a sessões de ECT, antipsicóticos e estabilizadores de humor. Foi-lhe informado que deveria tomar medicações para o resto da vida e parar completamente o uso de substâncias psicoativas, ou então correria o risco de machucar outras pessoas. Sua família ainda foi informada de que possivelmente Alek não conseguiria voltar à faculdade, e que suas oportunidades de trabalho seriam limitadas.

Alek nunca expressou nenhuma manifestação de agressividade durante seu período de internação, porém, esse foi um risco colocado constantemente para ele e sua família. Alek me questionava se ser violento e/ou agressivo era uma consequência de sua doença, e de que outras formas ela poderia influenciar e mudar sua cabeça. Apresentava intenso receio com relação a voltar para a faculdade, pois, embora tivesse muito desejo de fazê-lo, a equipe já tinha informada à sua família que ele não conseguiria voltar. Alek apresentava muitas dúvidas com relação à forma que essa doença implicaria no restante de sua vida, pois sua família recebia informações que ele próprio não recebia, ou até recebia o contrário.

Aproveitando do desejo de Alek por estudar, procurei em conjunto com ele por textos que dissessem respeito à outra leitura feita da Esquizofrenia e do fenômeno de escutar vozes. Realizamos leituras a partir de diversas abordagens, sendo que Alek se familiarizou com o estudo do método do Diálogo Aberto, desenvolvido por Jaakko Seikkula e sua equipe, na Finlândia, na década de 1980 (Kantorski e Cardano, 2017).

A partir desses estudos, Alek questionava muito o fato de ainda estar internado, pois já havia desenvolvido certas estratégias para se relacionar com as vozes que escutava. Já há três meses internado, Alek escreveu em seu 
caderno: "Eu não aguento mais. Preciso fugir deste lugar ou encontrar algum motivo para estar aqui". Alek constantemente omitia o fato de ainda estar ouvindo vozes ou vendo coisas, pois havia entendido que era por conta da permanência desses sintomas que ele ainda era mantido naquele espaço.

Além disso, Alek omitia não querer cessar o uso de SPAs para parte da equipe que colocou que sua aderência à abstinência era condicional para sua alta. A seu pedido, também trouxe trabalhos que relacionassem o uso de substâncias com sintomas psicóticos e, além destes, alguns trabalhos que traziam a abordagem de Redução de Danos. Mapeamos, dentro da sua cidade, pontos a que Alek poderia recorrer caso fizesse uso excessivo e sentisse necessidade de pedir ajuda, a depender do momento e gravidade em que se encontrava. Foi realizada, também, a discussão de caso com profissionais que se assumiram enquanto referência do caso de Alek nos respectivos serviços.

Alek ficou internado por um período total de quatro meses. Sua alta se deu com a avaliação de que ele estava mais "adequado" e já não apresentava sintomas psicóticos há algumas semanas - pois Alek escondia tais manifestações para parte da equipe. A equipe entendia como "adequado" a diminuição dos pedidos de Alek para fazer uso do telefone e para fazer as saídas para o espaço externo.

A concepção estigmatizada do sofrimento psíquico é fortalecida conforme as instituições - de poder e de saber, como a Psiquiatria tradicional sustentam que a incapacidade e consequente necessidade de submissão a outrem é atestada enquanto diagnóstico psiquiátrico. Há o respaldo científico da Psiquiatria tradicional que coloca o sujeito como um objeto instável e que, se não vigiado e controlado, pode a qualquer momento colocar em risco a estabilidade de outrem.

Dentro dos serviços de saúde, a necessidade de submissão, justificada por uma suposta incapacidade do sujeito de gerir a própria vida, se apresenta de diferentes maneiras: na imposição de determinada medicação para o usuário sem que este saiba para que ela serve, na elaboração de um Projeto Terapêutico 
Singular que não tenha como plano central o desejo do usuário, dentre outras ações que distanciam cada vez mais o sujeito de sua autonomia.

Todavia, não são mais os serviços de saúde os únicos mantenedores desse estigma: a sociedade como um todo também incorpora e expressa tal discurso aprisionador, que tira o louco de qualquer lugar que ele deseja ocupar. Não são somente os médicos, psicólogos, terapeutas ocupacionais, enfermeiros, diretores de hospitais que ditam as regras, mas também a família, os amigos, os chefes do trabalho, os vizinhos e a comunidade que acabam, de certa forma, por exercer essa violência que se estende para diferentes espaços na sociedade.

Retomando brevemente os estudos de Goffman (1961) acerca dos Manicômios, o autor descreve certa tensão entre o mundo institucional e o mundo "de fora" que, de certa forma, é usada pelas instituições como uma estratégia para controlar aqueles que estão internados. Para aquele que está internado, estar dentro do Manicômio inevitavelmente coloca a possibilidade de um fora. Porém, quando a violência aparece nas sutilezas do cotidiano, não há dentro nem fora, mas apenas um lugar em que dentro e fora se misturam, e não restam alternativas para esses sujeitos que não se transformarem no próprio Castanheiro.

Ainda que haja Reforma Psiquiátrica, se não houver a prática da luta antimanicomial que contemple uma nova forma de cuidar que aposte no desejo do sujeito, que promova cidadania, que construa um novo lugar social para o louco, que defenda a vida e suas diferentes formas de expressão e subjetivação, não há o que reste para esses sujeitos além da sua solidão.

\section{Os anos de solidão}


É possível reconhecer uma linha comum que enlaça todos os sujeitos aqui apresentados. Foram muitas as práticas de violência e exclusão que apareceram como propostas de cuidado e atravessaram a vida dessas pessoas em um momento de crise e vulnerabilidade. Para além disso, a forma como tais práticas foram conduzidas dentro desse espaço acabou por possivelmente impactar a vida dessas pessoas também na sua convivência em sociedade, atingindo de forma subjetiva a maneira como cada sujeito deseja conduzir sua vida e sua história. Em meio a tantos atravessamentos, parece inevitável pensar e considerar esse sentimento que passa a acometer a vida desses sujeitos quando direitos the são negados e desejos silenciados, que é o sentimento de solidão, solidão esta que está além do isolamento.

É uma solidão histórica a que acompanha esses sujeitos. Sob diferentes justificativas, são violentamente segregados tanto de forma física quanto subjetiva, contribuindo para a construção de uma cultura que não permite que o louco expresse a sua verdade tanto para uma sociedade quanto para consigo mesmo.

Na Enfermaria, parte da equipe avaliava a melhora dos usuários ali internados através de uma chamada "crítica" que eles deveriam obter em relação a seus sintomas. Essa crítica dizia respeito a quando o usuário não mencionava os sintomas que, de certa forma, poderiam causar prejuízos nas relações sociais. Assim, ao reconhecerem que necessitavam dessa crítica, tais sujeitos escolhem parar de expressar aquilo que Ihes acomete, entendendo que é só mantendo tais sofrimentos para si que é possível viver em sociedade.

Viver uma realidade que não é compartilhada pelos demais ao seu redor já pode ser solitário por si próprio. Se essa realidade em que tais sujeitos vivem for ignorada, vivenciada pelos outros como se não existisse, a solidão aumenta. Da mesma forma, não reconhecer a realidade vivida por esses sujeitos como diferentes é igualmente cruel. É necessário que se legitimem as diferentes experiências de se estar no mundo, fortalecendo acessos e 
possibilidades para que novos direitos sejam alcançados e garantidos.

Fechamos este capítulo final descrevendo outra cena de José Arcádio na obra de Gabriel Garcia Marquez. No começo da história, Macondo é descrita como um lugar isolado, com pouquíssimos visitantes. Dentre estes está Melquíades, com quem José Arcádio se impressionava devido a seus truques e sua sabedoria.

Melquíades retorna para Macondo depois de um tempo sem visitá-los, e José Arcádio se surpreende com o que vê: o amigo, antes banguela, agora tem dentes. Ao ver o amigo impressionado, Melquíades revela sua dentadura, explica seu mecanismo e informa que essa é uma tecnologia já bastante desenvolvida no mundo afora. José Arcádio continua impressionado, mas se revolta: se deparou com o quanto estavam sozinhos, isolados do restante do mundo, enfurnados em Macondo.

Sua reação foi logo interpretada como um surto de loucura pela comunidade: convocou os homens do povoado para o acompanharem no que seria o desbravamento de um novo mundo. Inconformado com a solidão de seu povo, a aventura para a qual estavam se dirigindo era para a construção de uma estrada que ligasse Macondo a um novo universo de tecnologias e modernidades, abrindo, de uma vez por todas, um caminho de comunicação entre esses dois mundos, tirando seu povo da solidão.

Não seria essa expressão da loucura, também, uma tentativa de se salvar dessa solidão que é constantemente imposta para esses sujeitos? Uma tentativa de se tornar livre do isolamento, de ser visto, de legitimar um sofrimento? Não basta mais a garantia de direitos de acesso a serviços de saúde e assistência, se um discurso que permanece aprisionando sujeitos ainda é legitimado dentro da nossa sociedade através dessas práticas, que não dão outra oportunidade para os loucos que não a de serem, para sempre, loucos e doentes.

Apesar de tantas mudanças nas formas de propor tratamento em Psiquiatria ou Saúde Mental, o medo do isolamento, 
punição e controle ainda atravessa essa população marginalizada que está sob constantes ataques. Se o fantasma do encarceramento da loucura ainda assombra aqueles que são acometidos por ela, é também porque ele mantémse atualizado pelo decorrer da história em diferentes formas. O Manicômio nem sempre vem em forma de concreto - às vezes vem em forma de Castanheiro. Vem em forma de preconceitos, de repressão, ideologias, leis. Pode vir em forma de religião, pode vir fantasiado de cuidado. Vem em forma de falta: de acesso, oportunidade, recursos, direitos. $E$ às vezes vem em forma de governo.

Que nossa luta seja direcionada para uma sociedade em que a singularidade dentro de um coletivo seja de fato respeitada e preservada, para que os povos condenados à solidão tenham, finalmente e para sempre, novas possibilidades sobre a terra

\section{Referências}

Brasil. (1988). Constituição da República Federativa do Brasil. Diário Oficial da União, 5 de outubro.

Brasil. (2001). Presidência da República. Lei nº 10.216, de 6 de abril de 2001. Dispõe sobre a proteção e os direitos das pessoas portadoras de transtornos mentais e redireciona o modelo assistencial em saúde mental. Diário Oficial da União, 9 de abril.

Costa Junior, F. \& Medeiros, M. (2007). Alguns conceitos de loucura entre a Psiquiatria e a Saúde Mental: diálogo entre os opostos? Psicologia USP, 18 (1), 57-82. 
Emerich, B. F., Campos, R. O. \& Passos, E. (2014). Direitos na Loucura: o que dizem usuários e gestores dos Centros de Atenção Psicossocial (CAPS), Interface, 18(51), 685-96.

Ferrazza, D. A. (2013). A psiquiatrização da existência: dos manicômios à neuroquímica da subjetividade. Tese de Doutorado, Faculdade de Ciências e Letras de Assis, UNESP, Assis -SP.

Goffmann, E. (1961). Manicômios, prisões e conventos. São Paulo: Editora Perspectiva S.A. Kantorski, L. P. \& Cardano, M. (2017). Diálogo Aberto: a experiência finlandesa e suas contribuições, Saúde debate, 41(112).

Kimati, M., Ferigato, S. \& Chanchetti, M. (2019). O papel da enfermaria de saúde mental em hospital geral: costurando possibilidades em rede. In Emerich, B. F. \& Onocko-Campos, R. T. SaúdeLoucura,10, São Paulo: Editora Hucitec.

Marquez, G. G. (1973). Cem anos de solidão. $22^{a}$ ed. Rio de Janeiro: Editora Record.

Silva, J. L. P. da. (2012). Eletroconvulsoterapia, não. Eletrochoque, Responsabilidades, 2 (1), 35-54.

Yasui, S. (2009). A atenção psicossocial e os desafios do contemporâneo: um outro mundo é possível, Cad. Bras. Saúde Mental, 1(1), 2009.

Recebido em: 08/08/2020 Aprovado em: 15/12/2020 